\title{
Changed Diabetic Treatment from Multiple Daily Injection (MDI), Dulaglutide to Xultophy
}

\author{
Hiroshi Bando $^{1,2^{*}}$, Yoshinobu Kato ${ }^{2}$, Yoshikane Kato ${ }^{2}$, Sayuri Matsuzaki ${ }^{2}$, Shinnichi Waka ${ }^{2}$, Katsunori Ogura ${ }^{2}$ \\ ${ }^{1}$ Tokushima University/Medical Research, Tokushima, Japan \\ ${ }^{2}$ Kanaiso Hospital, Komatsushima, Tokushima, Japan
}

Corresponding Author: Hiroshi BANDO, MD, PhD, FACP ${ }^{\text {ORCID iD }}$

Address: Tokushima University/Medical Research, Nakashowa 1-61, Tokushima 770-0943, Japan.

Received date: 19 February 2021; Accepted date: 29 March 2021; Published date: 06 April 2021

Citation: Bando H, Kato Y, Kato Y, Matsuzaki S, Waka S, Ogura K. Changed Diabetic Treatment from Multiple Daily Injection (MDI), Dulaglutide to Xultophy. Asp Biomed Clin Case Rep. 2021 Apr 06;4(1):77-83.

Copyright (C) 2021 Bando H, Kato Y, Kato Y, Matsuzaki S, Waka S, Ogura K. This is an open-access article distributed under the Creative Commons Attribution License, which permits unrestricted use, distribution, and reproduction in any medium provided the original work is properly cited.

\begin{abstract}
The patient is a 56-year old (yo) female with type 2 diabetes mellitus (T2DM). Medical histories include persisting T2DM from 35yo, renal stone at 43yo, hypertension from 45yo, photocoagulation for retinopathy on 54yo. An incidentaloma was found in the left adrenal gland, where endocrinological exams were negative for functional tumor. Her diabetic control situation became worse with $\mathrm{HbA1c}>10 \%$, then the treatment has been changed from multiple daily injection (MDI), Dulaglutide to Xultophy which is combined agents of degludec and liraglutide (IDegLira). It was provided 10-18 doses daily, and then glucose variability profile was improved satisfactory, suggesting the dual synergistic effects.
\end{abstract}

\section{Keywords}

Xultophy, Degludec and Liraglutide, Glucagon-Like Peptide 1 (GLP-1) Receptor Agonist, Dual Action of Liraglutide and Insulin Degludec, European Xultophy Treatment Retrospective Audit

\section{Abbreviations}

IDegLira: Degludec and Liraglutide; GLP-1RA: Glucagon-Like Peptide 1 (GLP-1) Receptor Agonist; DUAL: Dual Action of Liraglutide and Insulin Degludec; EXTRA: European Xultophy Treatment Retrospective Audit

\section{Introduction}

Diabetes has been one of the crucial noncommunicable diseases (NCDs) across the world [1]. Its prevalence has been increasing in developed and developing countries [2]. It may bring a variety of influences in the light of medical and economic aspects [3]. Regarding diabetic treatments, several options have been introduced, including oral hypoglycemic agents (OHAs) and injectable agents [4].

For the development of various treatment agents for diabetes, a recent important topic includes glucagon- like peptide 1 (GLP-1) receptor agonist (GLP-1RA) [5]. After GLP-1RA showed clinical efficacy for diabetes, the combination of basal insulin and GLP-1RA was proposed for more beneficial efficacy [6]. There have been fixed-ratio combined agents with basal degludec and liraglutide and are known as Xultophy (IDegLira) [7].

Its beneficial effects of these combined agents are observed [6]. In other words, they show complementary efficacy on glucose variability from degludec and liraglutide. The former degludec can 
lower fasting plasma glucose (FPG), and the latter can lower FPG and decrease postprandial glucose response [8]. Moreover, the latter can improve beta-cell function and restore prandial insulin response/cardioprotective properties [9].

As to the fixed-ratio combination of IDegLira, there was a study of the DUAL (Dual Action of Liraglutide and Insulin Degludec) clinical trial program [10,11]. The safety and effect were investigated in a series of DUAL programs. They showed that the superior or noninferior glycemic control was found with several comparators, associated with the benefit for lower risk of hypoglycemia and weight gain in comparison with other insulin agents $[12,13]$.

Regarding diabetic practice, authors and collaborators have continued a variety of research. They include low carbohydrate diet (LCD), calorie restriction (CR), meal tolerance test (MTT), continuous glucose monitoring (CGM), treatment of insulin, GLP1 RA and Xultophy, and so on $[14,15]$. Especially, we have applied Xultophy to patients with multiple problems and dialysis $[16,17]$. Xultophy has been known to be clinically effective for patients with various diseased states such as renal insufficiency or chronic renal failure, or limited treatment options [18]. This would be due to the beneficial efficacy of combined pharmacological agents. Authors have experienced an impressive diabetic case who has changed the treatment of multiple daily injection (MDI) insulin therapy to dulaglutide and also to Xultophy. In this article, general clinical progress associated with some discussion will be presented.

\section{Case Presentation}

Present History:

The patient is a 56-year old female. As a medical history, diabetes was detected at 35 years old (yo), urinary tract stones at 43 yo, hypertension from 45 yo, photocoagulation for diabetic retinopathy from 54 yo, and surgery for cataract at 55 yo. A space-occupying lesion (SOL) $2 \mathrm{~cm}$ in size was found in her left adrenal gland at a medical examination in June 2020. An endocrinological examination for adrenal tumors was performed at another hospital in July. As a result, the excessive concentration of cortisol and catecholamine was denied. The value of HbA1c has been elevated at a high value of $8-9 \%$.

\section{Physical Examination:}

Her consciousness was alert, and her vitals are stable, such as body temperature 36.8 , pulse $87 / \mathrm{min}$, BP 112/67 mmHg. Her physique showed stature 151.2 $\mathrm{cm}$, weight $58.6 \mathrm{~kg}$, standard weight $50.2 \mathrm{~kg}$, BMI 25.6 $\mathrm{kg} / \mathrm{m}^{2}$, abdominal circumference $87 \mathrm{~cm}$. Skin showed normal turgor, no thyromegaly, no swollen lymph nodes. Conjunctiva was not anemic or icteric. Her chest showed regular rate rhythm in the heart and no rale in the lung. The abdomen was slightly distended, and extremities showed no pretibial edema. There were no clear signs of the moon face, buffalo hump, or central obesity. Neurologically, there were no sensory abnormalities such as peripheral neuropathy.

\section{Examination Data:}

The results of laboratory exams were shown in the following. The standard biochemical data were GOT 23 U/mL, GPT 27 U/mL, r-GTP 24 U/mL, Cre 0.7 mg/dL, BUN $19 \mathrm{mg} / \mathrm{dL}$, Uric Acid $5.6 \mathrm{mg} / \mathrm{dL}$, HDL-C 40 $\mathrm{mg} / \mathrm{dL}$, LDL-C $105 \mathrm{mg} / \mathrm{dL}$, Triglyceride $298 \mathrm{mg} / \mathrm{dL}$, RBC $4.37 \times 10^{6} / \mu \mathrm{L}, \mathrm{Hb} 13.3 \mathrm{~g} / \mathrm{dL}$, WBC $5400 / \mu \mathrm{L}$, Plt $23.9 \times 10^{4} / \mu \mathrm{L}$. Data concerning diabetes showed HbA1c 9.0\%, post-prandial glucose $283 \mathrm{mg} / \mathrm{dL}$.

Other examinations were as follows: i) ECG: pulse 76/min, ordinary sinus rhythm, no ST-T changes, ii) chest X-ray: WNL, iii) Ankle brachial index (ABI) / Pulse wave velocity (PWV): ABI showed 1.22/1.26 (r/l), and PWV 1715/1864 (>+2SD), iv) Coefficient of variation of $\mathrm{R}-\mathrm{R}$ interval (CV R-R): it was 3.0\% (normal is $=<2.0$ ), v) renal examination: Ccr 80.2 $\mathrm{ml} / \mathrm{min}$, Urinary-Albumin $10.8 \mathrm{mg} /$ day, serum CPR $1.71 \mathrm{ng} / \mathrm{ml}$, vi) urinary C-peptide $92 \mu \mathrm{g} /$ day (35-140).

\section{Clinical Progress}

This case has T2DM and other problems. She was pointed out $(\mathrm{P} / \mathrm{O})$ the presence of left adrenal incidentaloma, and after that, the possibility of Cushing syndrome was ruled out (R/O) (Fig-1). She has been provided Ipragliflozin L-proline (Sugra ${ }^{\circledR}$, 5omg) 1 Tablet and Voglibose (Basen ${ }^{\circledR}$, o.3mg) 2 Tablets in the morning and evening as oral hypoglycemic agents (OHAs) for long period. For 
Citation: Bando H, Kato Y, Kato Y, Matsuzaki S, Waka S, Ogura K. Changed Diabetic Treatment from Multiple Daily Injection (MDI), Dulaglutide to Xultophy. Asp Biomed Clin Case Rep. 2021 Apr o6;4(1):77-83.

\section{Case Report}

injectable agents, she has given i) insulin glargine 10 units and Apidra 17-25-18 units, which was MDI insulin therapy, ii) Deglutide $0.75 \mathrm{mg} /$ week, iii) Xultophy 10-18 doses/day as shown in Fig-1. HbA1c value was $9.0 \%$ to $7.8 \%$ in $\mathrm{MDI}, 7.8 \%$ to $10.6 \%$ in Deglutide, and $10.6 \%$ to $8.2 \%$ in Xultophy.

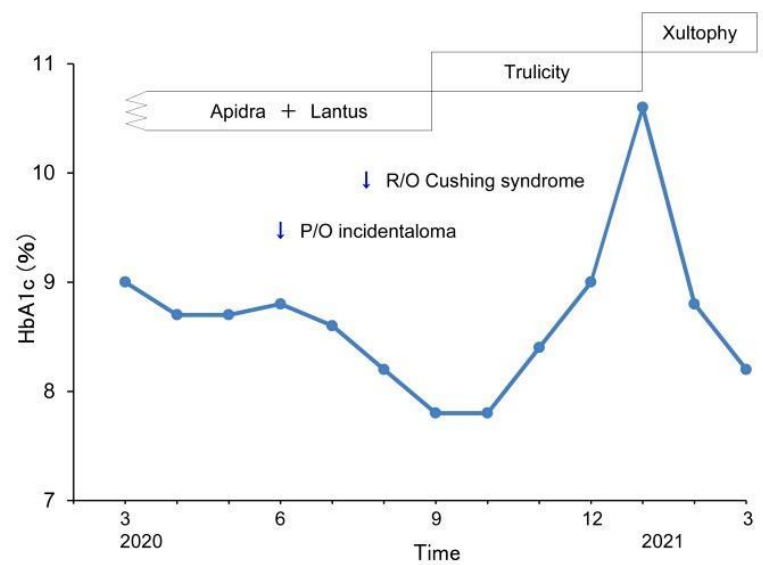

Fig-1: Clinical progress with the changes of HbAic and treatment

When changing the treatment from Deglutide to Xultophy, the daily profile of blood glucose was studied for 2 weeks. The results are shown in Table-1. Dulaglutide has its clinical effect for 7 days, and glucose levels ranged from $159 \mathrm{mg} / \mathrm{dL}$ to $208 \mathrm{mg} / \mathrm{dL}$ during days 6-8 after the injection of Dulaglutide. Xultophy was started at 10 doses and gradually increased its dose. Glucose variability was improved for $108 \mathrm{mg} / \mathrm{dL}$ to $144 \mathrm{mg} / \mathrm{dL}$ for $11-12$ days of administration.

\section{Problems Lists:}

Her current medical problems and treatment are summarized in the following.

1. T2DM: She has been provided OHAs and three injectable agents during the course (Fig-1).

2. Hypertension: Her blood pressure has been controlled by the administration of two antihypertensive agents (AHA), including Irbesartan 10omg and trichlormethiazide $1 \mathrm{mg}$.

3. Hyperlipidemia: She was given Rosuvastatin (Crestor $^{\circledR}, 2.5 \mathrm{mg}$ ) with rather stable control of LDL-C, TG and HDL-C [19].

4. Osteoarthritis (OA) of the knees: She has felt pain in the knees. Current treatment includes Celecoxib (Celecox ${ }^{\circledR}$, 10omg) 2 Tablets per day and pregabalin (Lyrica ${ }^{\circledR} 75 \mathrm{mg}$ ) 2 Tablets per day [20].

\begin{tabular}{|c|c|c|c|c|c|}
\hline \multicolumn{6}{|c|}{ Table-1: Changes in blood glucose for Xultophy treatment } \\
\hline \multirow{2}{*}{ Day } & \multicolumn{3}{|c|}{ Blood Glucose (mg/dL) } & \multirow{2}{*}{$\begin{array}{c}\text { Xultophy } \\
\text { dose }\end{array}$} & \multirow{2}{*}{$\begin{array}{c}\text { Dulaglutide } \\
0.75 \mathrm{mg} / \mathrm{w}\end{array}$} \\
\hline & Morning & Noon & Evening & & \\
\hline 1 & & & 159 & & day 6 \\
\hline 2 & 194 & 196 & 166 & & day 7 \\
\hline 3 & 208 & 188 & 172 & & day 8 \\
\hline 4 & 189 & 164 & 175 & 10 & \\
\hline 5 & 190 & 181 & 193 & 12 & \\
\hline 6 & 149 & 149 & 252 & 14 & \\
\hline 7 & 174 & 140 & 149 & 14 & \\
\hline 8 & 149 & 115 & 174 & 16 & \\
\hline 9 & 126 & 107 & 118 & 16 & \\
\hline 10 & 131 & 122 & 162 & 16 & \\
\hline 11 & 135 & 91 & 102 & 17 & \\
\hline 12 & 119 & 111 & 101 & 17 & \\
\hline 13 & 140 & 147 & 165 & 17 & \\
\hline 14 & 124 & 111 & 144 & 17 & \\
\hline 15 & 108 & 110 & & 18 & \\
\hline
\end{tabular}




\section{Discussion}

This report is concerning to clinical efficacy of Xultophy, which contains basal-bolus insulin and GLP1RA. Several papers were found about the comparative study of basal insulin and Xultophy. Previous outcomes of Xultophy were broadly aligned with the results of DUAL studies. They showed a significant decrease in HbA1c, reducing the tendency of body weight, lower risk of hypoglycemia episodes for half years in comparison with baseline regimens [21]. Despite being an efficacious glucose-lowering therapy, basal-bolus treatment is associated with a higher rate of hypoglycemia versus other anti-diabetes therapies [22].

In the European region, there has been the European Xultophy Treatment Retrospective Audit (EXTRA) study. Some real-world evidence (RWE) studies (EXTRA) showed that a significant HbA1c reduction $(-0.7 \%)$ and weight reduction $(-2.4 \mathrm{~kg})$ were found for half a year, in patients with changing treatment from MDI to Xultophy [23]. There is a recent study by Persano et al. (2021) [24]. T2DM patients had changed from basal-bolus insulin treatment to Xultophy starting with 16 doses. Subjects were trained to titrate the dose twice weekly to maintain 90-130 $\mathrm{mg} / \mathrm{dL}$ fasting target glucose level. Their adjustments were made 2 doses at a time. The results showed that HbA1c values were 8.4 vs $7.4 \%$ in the control and Xultophy group in 6 months [24].

Regarding the background of the case, it is important to evaluate the situation of diabetic complications for microangiopathy and macroangiopathy. She has proliferative retinopathy with the treatment of photocoagulation and the operation of cataract but did not have clear evidence of neuropathy, nephropathy, or macroangiopathy of the brain, heart, and peripheral artery. When she received a health check-up in the spring of 2020, left adrenal incidentaloma was found. Several endocrinological tests showed negative results in plasma aldosterone concentration (PAC), plasma renin activity (PRA), $\mathrm{PAC} / \mathrm{PRA}$ ratio [25], ACTH and cortisol values, overnight dexamethasone suppression test (1mg), and serum and urine catecholamine concentration. It was unlikely to exist the presence of Cushing's syndrome, pheochromocytoma, or primary aldosteronism (PA) [26]. Therefore, it was considered to be a nonfunctioning adenoma.

She has been treated for hypertension for a long. Her usual situation of blood pressure was stable with medication, not a fluctuating type, not clinical symptoms like pheochromocytoma, and catecholamine levels were within the normal range [27]. Since Cushing's disease is also negative, it is considered to be essential hypertension rather than secondary hypertension. Regarding dyslipidemia, triglyceride has been high for some time. In other words, it is thought to be associated with obesity and metabolic syndrome, and LDL-C is currently in the normal range by taking Crestor. A recent study showed the significant predominance of Rosuvastatin over atorvastatin in reducing LDL in T2DM as a mean reduction of $30.5 \mathrm{vs}$ $29.6 \mathrm{mg} / \mathrm{dL}$ for 6 weeks $(\mathrm{p}<0.01)$ [28].

Her current clinical course showed the exacerbation of HbA1c after changed to the treatment of Dulaglutide, and then the treatment of Xultophy was started. As the initial amount of Xultophy, 10 or 16 doses has been the standard value in a patient with insulin naïve or experienced case, respectively [29]. Furthermore, there may be another perspective that the standard starting dose would be 16 doses in Europe or 10 doses in Japan. This case is a Japanese woman with rather a small physique, then the starting dose was set to 10 doses. Furthermore, authors have various experiences to provide Xultophy T2DM patients with various situations and complications $[16,17]$. The method to titrate would be to control the doses every 3-4 days based on FPG. In the study of DUAL V, attended cases had adjusted the doses on Monday and Thursday of each week [10]. The maximum doses of Xultophy would be 50 doses, which means 50 units of Degludec and $1.8 \mathrm{mg}$ of liraglutide [13,29]. As to the continuation of Xultophy, 2432 T2DM cases were investigated for 18 months. The results showed that $84 \%$ of cases continued Xultophy, associated with a mean reduction of $\mathrm{HbA1C} 1 \%$, and weight reduction 1.1 $\mathrm{kg}$, by 33 mean doses [30].

In summary, this article showed the impressive clinical progress of the changes in HbA1c and diabetic 
agents from MDI, Dulaglutide to Xultophy. Xultophy may have dual synergistic effects of degludec and liraglutide (IDegLira). Consequently, combined treatment of insulin and GLP-1RA seemed to be effective for improving the glucose variability. This report will be hopefully one of the reference data for a future diabetic research study.

\section{Funding}

There was no funding received for this paper.

\section{Conflicts of Interest}

All authors have read and approved the final version of the manuscript. The authors have no conflicts of interest to declare.

\section{References}

[1] International Diabetes Federation. Belgium: IDF Diabetes Atlas 9th edition; 2019. Available from: https://idf.org/aboutdiabetes/what-is-diabetes/factsfigures.html

[2] Smokovski I. Managing Diabetes in Low Income Countries: Providing Sustainable Diabetes Care with Limited Resources. Springer Nature; 2020.

[3] Williams R, Karuranga S, Malanda B, Saeedi P, Basit A, Besançon S, Bommer C, Esteghamati A, Ogurtsova K, Zhang P, Colagiuri S. Global and regional estimates and projections of diabetes-related health expenditure: Results from the International Diabetes Federation Diabetes Atlas, 9th edition. Diabetes Res Clin Pract. 2020 Apr;162:108072. [PMID: 32061820]

[4] American Diabetes Association. 9. Pharmacologic Approaches to Glycemic Treatment: Standards of Medical Care in Diabetes-2021. Diabetes Care. 2021 Jan;44(Suppl 1):S111-S24. [PMID: 33298420]

[5] $\mathrm{Yu} \mathrm{M,} \mathrm{Benjamin} \mathrm{MM,} \mathrm{Srinivasan} \mathrm{S,} \mathrm{Morin} \mathrm{EE,}$ Shishatskaya EI, Schwendeman SP, Schwendeman A. Battle of GLP-1 delivery technologies. Adv Drug Deliv Rev. 2018 May;130:113-30. [PMID: 30009885]

[6] Cohen ND, Audehm R, Pretorius E, Kaye J, Chapman LH, Colagiuri S. The rationale for combining GLP-1 receptor agonists with basal insulin. Med J Aust. 2013 Aug 19;199(4):246-49. [PMID: 23984780]

[7] Novo Nordisk Inc. Xultophy 100/3.6 (insulin degludec and liraglutide) Injection. United States: U.S. Food and Drug Administration; 2017 Nov 27 [cited
2021 Feb 18]. Available from:

https://www.accessdata.fda.gov/drugsatfda_docs/nda /2016/208583Orig1soooTOC.cfm

[8] Novo Nordisk. Xultophy FDA Approval History. Drugs.com; 2021 [cited 2021 Feb 18]. Available from: https://www.drugs.com/history/xultophy.html

[9] Marso SP, Daniels GH, Brown-Frandsen K, Kristensen P, Mann JF, Nauck MA, Nissen SE, Pocock S, Poulter NR, Ravn LS, Steinberg WM, Stockner M, Zinman B, Bergenstal RM, Buse JB; LEADER Steering Committee; LEADER Trial Investigators. Liraglutide and Cardiovascular Outcomes in Type 2 Diabetes. N Engl J Med. 2016 Jul 28;375(4):311-22. [PMID: 27295427]

[10] Lingvay I, Pérez Manghi F, García-Hernández P, Norwood P, Lehmann L, Tarp-Johansen MJ, Buse JB; DUAL V Investigators. Effect of Insulin Glargine Uptitration vs Insulin Degludec/Liraglutide on Glycated Hemoglobin Levels in Patients With Uncontrolled Type 2 Diabetes: The DUAL V Randomized Clinical Trial. JAMA. 2016 Mar 1;315(9):898-907. 2016 May 17;315(19):2125. Tigkas, Stelios [corrected to Tigas, Stelios]. 2016 May 17;315(19):2125. Tigkas, Stelios [corrected to Tigas, Stelios]. [PMID: 26934259]

[11] Rodbard HW, Bode BW, Harris SB, Rose L, Lehmann L, Jarlov H, Thurman J; Dual Action of Liraglutide and insulin degludec (DUAL) IV trial investigators. Safety and efficacy of insulin degludec/liraglutide (IDegLira) added to sulphonylurea alone or to sulphonylurea and metformin in insulinnaïve people with Type 2 diabetes: the DUAL IV trial. Diabet Med. 2017 Feb;34(2):189-96. [PMID: 27589252]

[12] Harris SB, Kocsis G, Prager R, Ridge T, Chandarana K, Halladin N, Jabbour S. Safety and efficacy of IDegLira titrated once weekly versus twice weekly in patients with type 2 diabetes uncontrolled on oral antidiabetic drugs: DUAL VI randomized clinical trial. Diabetes Obes Metab. 2017 Jun;19(6):858-65. [PMID: 28124817]

[13] Billings LK, Doshi A, Gouet D, Oviedo A, Rodbard HW, Tentolouris N, Grøn R, Halladin N, Jodar E. Efficacy and Safety of IDegLira Versus Basal-Bolus Insulin Therapy in Patients With Type 2 Diabetes Uncontrolled on Metformin and Basal Insulin: The DUAL VII Randomized Clinical Trial. Diabetes Care. 2018 May;41(5):1009-16. [PMID: 29483185] 
[14] Bando H, Muneta T, Bando M, Yonei Y. Effect of low carbohydrate diet on type 2 diabetic patients and usefulness of M-value. Diabetes Research: Open Journal. 2017 Feb 13;3(1):9-16.

[15] Ebe K, Bando H, Muneta T, Bando M, Yonei Y. Remarkable improvement of glucose variability by Sodium-glucose cotransporter 2 (SGLT2) inhibitors using continuous glucose monitoring (CGM). Diabetes Case Rep. 2019 Jan 28;4(1):1-5.

[16] Kato Y, Bando H, Yamashita H, Yada S, Tokuhara S, Tokuhara H, Mutsuda T. Impressive clinical course of diabetic patient with various medical problems and remarkable improvement by insulin degludec and liraglutide (Xultophy). MOJ Clin Med Case Rep. 2020 Apr 30;10(2):48-51.

[17] Fujikawa T, Kato Y, Bando H, Kakutani H, Kawata T, Yamamoto M, Wada K, Ishikura K, Shirai Y, Narutaki M, Matsuzaki S, Waka S. The Administration of Xultophy for Diabetic Patients on Hemodialysis. Diab Res Open Access. 2020 Oct 20;2(3):72-78.

[18] Tibaldi J, Mercado ME, Strong J. How Effective Is the Fixed-Ratio Combination of Insulin Degludec and Liraglutide (IDegLira) in Different Patient Populations, and When Should It Be Used in Clinical Practice? Clin Diabetes. 2020 Oct;38(4):339-47. [PMID: 33132503]

[19] Yusuf S, Bosch J, Dagenais G, Zhu J, Xavier D, Liu L, Pais P, López-Jaramillo P, Leiter LA, Dans A, Avezum A, Piegas LS, Parkhomenko A, Keltai K, Keltai M, Sliwa K, Peters RJ, Held C, Chazova I, Yusoff K, Lewis BS, Jansky P, Khunti K, Toff WD, Reid CM, Varigos J, Sanchez-Vallejo G, McKelvie R, Pogue J, Jung H, Gao P, Diaz R, Lonn E; HOPE-3 Investigators. Cholesterol Lowering in Intermediate-Risk Persons without Cardiovascular Disease. N Engl J Med. 2016 May 26;374(21):2021-31. [PMID: 27040132]

[20] Wiffen PJ, Derry S, Bell RF, Rice AS, Tölle TR, Phillips T, Moore RA. Gabapentin for chronic neuropathic pain in adults. Cochrane Database Syst Rev. 2017 Jun 9;6(6):CDoo7938. [PMID: 28597471]

[21] Price H, Blüher M, Prager R, Phan TM, Thorsted BL, Schultes B; EXTRA study group. Use and effectiveness of a fixed-ratio combination of insulin degludec/liraglutide (IDegLira) in a real-world population with type 2 diabetes: Results from a European, multicentre, retrospective chart review study. Diabetes Obes Metab. 2018 Apr;20(4):954-62 [PMID: 29205856]

[22] Melzer-Cohen C, Chodick G, Naftelberg S, Shehadeh N, Karasik A. Metabolic Control and Adherence to Therapy in Type 2 Diabetes Mellitus Patients Using IDegLira in a Real-World Setting. Diabetes Ther. 2020 Jan;11(1):185-96. [PMID: 31808132]

[23] Taybani Z, Bótyik B, Katkó M, Gyimesi A, Várkonyi T. Simplifying Complex Insulin Regimens While Preserving Good Glycemic Control in Type 2 Diabetes. Diabetes Ther. 2019 Oct;10(5):1869-78. [PMID: 31347100]

[24] Persano M, Nollino L, Sambataro M, Rigato M, Negro I, Marchetto S, Paccagnella A. Real-world study on the effectiveness and safety of basal insulin IDegLira in type 2 diabetic patients previously treated with multi-injective insulin therapy. Eur Rev Med Pharmacol Sci. 2021 Jan;25(2):923-31. [PMID: 33577047]

[25] Kawashima J, Araki E, Naruse M, Kurihara I, Takahashi K, Tamura K, Kobayashi H, Okamura S, Miyauchi S, Yamamoto K, Izawa S, Suzuki T, Tanabe A. Baseline Plasma Aldosterone Level and Renin Activity Allowing Omission of Confirmatory Testing in Primary Aldosteronism. J Clin Endocrinol Metab. 2020 May 1;105(5):dgaa117. [PMID: 32157288]

[26] Teruyama K, Naruse M, Tsuiki M, Kobayashi H. Novel chemiluminescent immunoassay to measure plasma aldosterone and plasma active renin concentrations for the diagnosis of primary aldosteronism. Journal of Human Hypertension. 2021 Feb 9:1-9.

[27] Uketa S, Shimizu Y, Ogawa K, Utsunomiya N, Asai S, Ishihara M, Kanamaru S. Black adrenal adenoma causing subclinical Cushing's syndrome complicated with pheochromocytoma. IJU Case Rep. 2020 Dec 3;4(1):56-58. [PMID: 33426500]

[28] Javed M, Mohammad D, Iftikhar M, Jameel M, Masood Z, Ahmed N. To compare rosuvastatin with atorvastatin in terms of mean change in LDL-C in patient of diabetes mellitus. The Professional Medical Journal. 2020 Jul 10;27(07):1505-10.

[29] See how Xultophy® 100/3.6 takes glycemic control a step further for adults with T2D. United States: Xultophy10o/3.6; 2021. Available from: https://www.xultophy10036pro.com/ 
Citation: Bando H, Kato Y, Kato Y, Matsuzaki S, Waka S, Ogura K. Changed Diabetic Treatment from Multiple Daily Injection (MDI), Dulaglutide to Xultophy. Asp Biomed Clin Case Rep. 2021 Apr o6;4(1):77-83.

\section{Case Report}

[30] Eliasson B, Ekelund J, Miftaraj M, Ranthe MF,Mårdby AC, Da Rocha Fernandes JD, Svensson AM.Persistence with IDegLira in Patients in Clinical Practice: A Nationwide Observational Study in Sweden. Diabetes Ther. 2020 Aug;11(8):1807-20. [PMID: 32617849]

Keywords: Xultophy, Degludec and Liraglutide, Glucagon-Like Peptide 1 (GLP-1) Receptor Agonist, Dual Action of Liraglutide and Insulin Degludec, European Xultophy Treatment Retrospective Audit 